\title{
Stereospecific Taurine Conjugation of the trans-OH Metabolite (Active Metabolite) of CS-670, a New 2-Arylpropionic Acid Nonsteroidal Anti-inflammatory Drug, in Dogs
}

\author{
Masato Asami, ${ }^{a}$ Wataru TAKasaki, ${ }^{a}$ Haruo Iwabuchi,${ }^{a}$ Hideyuki Haruyama, ${ }^{a}$ \\ Kazuyuki WACHI, ${ }^{b}$ Atusuke TeradA, ${ }^{b}$ and Yorihisa TANAKA ${ }^{*, a}$ \\ Analytical and Metabolic Research Laboratories ${ }^{a}$ and Medicinal Chemistry Research Laboratories, ${ }^{b}$ Sankyo Co., \\ Ltd., 2-58, Hiromachi 1-chome, Shinagawa-ku, Tokyo 140, Japan. \\ Received March 20, 1995; accepted August 8, 1995
}

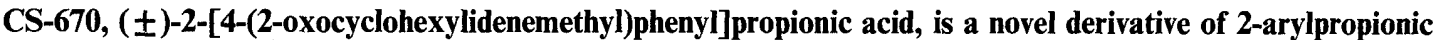
acid non-steroidal anti-inflammatory drugs (profen NSAIDs). The major urinary metabolite of this drug from dogs was isolated and its chemical structure was determined by MS and NMR spectroscopy. The metabolite was identified as a taurine conjugate of the trans- $\mathrm{OH}$ form (trans-OH-taurine) which was first generated by stereoselective reduction of the double bond and the carbonyl function of the CS-670 molecule. The taurine conjugate was excreted in urine as the main metabolite, regardless of the optical configuration of CS-670 administered [(2R)-enantiomer: $47.2 \%$ of the dose, $(2 S)$-enantiomer: $70.9 \%$ of the dose].

The trans-OH-taurine was hydrolyzed by refluxing it in $6 \mathrm{~N} \mathrm{HCl}$ without racemization. The released trans-OH

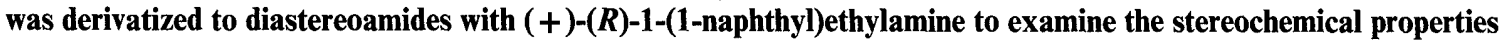
of the 2-arylpropionic acid side chain. It was found that the configuration of the 2-carbon of the trans-OH-taurine was almost entirely $(S)$. As the CoA thioesters are obligate intermediates for amino acid conjugation, the results suggest that the (2S)-enantiomer of the trans-OH metabolite serves as a substrate for canine acyl CoA ligase (EC 6.2.1.3) as well as the (2R)-enantiomer, but only the $\mathrm{CoA}$ thioester with a (2S)-configuration is a substrate for taurine $N$-acyl transferase. It is interesting to note that these results are not consistent with the chiral inversion mechanism by which the $(2 R)$-enantiomers of profen NSAIDs are stereospecifically converted to CoA thioester intermediates.
\end{abstract}

Key words CS-670; taurine conjugate; stereoselective metabolism

CS-670, ( \pm )-2-[4-(2-oxocyclohexylidenemethyl)phenyl]propionic acid, with an $\alpha, \beta$-unsaturated ketone group in its structure, is a novel non-steroidal anti-inflammatory drug. From the results obtained up to now on the disposition of CS-670, marked species differences have been demonstrated to exist in the metabolism of this compound. Namely, the mono-ols (cis-, trans-OH and unsaturated-OH ), which are produced by a reduction of the double bond and ketone group of CS-670, were further metabolized to diols by cytochrome P-450 in rats. ${ }^{1,2)}$ However, in mice and dogs they were mainly metabolized to the conjugated metabolites. ${ }^{1)}$ The conjugation reaction in mice was found to be glucuronic acid conjugation, but there has not been any information regarding the dog urinary conjugated metabolite other than that was not hydrolyzed with Glusulase.

In this report, we describe the structural determination of the conjugated metabolite isolated from dog urine by FAB-MS and ${ }^{1} \mathrm{H}-\mathrm{NMR}$. We also give the absolute configuration of the propionic acid side chain of the metabolite.

\section{MATERIALS AND METHODS}

Chemicals CS-670, trans-OH-taurine and their optical isomers were synthesized in the Medicinal Chemistry Research Laboratories at Sankyo. The optical purity of CS-670 enantiomers determined by the methods mentioned below was $99.0 \%$ ee for both enantiomers. The specific radioactivity of ${ }^{14} \mathrm{C}$-CS-670, labelled at the

* To whom correspondence should be addressed. methyl group of the 2-propionic acid side chain, was $1.18 \mathrm{MBq} / \mathrm{mg}$. The radiochemical purity was more than $98.6 \%$ determined by TLC on a Kieselgel $60 \mathrm{~F}_{254}$ plate (Merck, thickness $0.25 \mathrm{~mm}$ ) using benzene-acetone-acetic acid (87:10:3) and chloroform-acetic acid (19:1). Glusulase ( $\beta$-glucuronidase; 140000 units $/ \mathrm{ml})$ was purchased from DuPont Company (Wilmington, U.S.A.). (+)-(R)-1-(1-Naphthyl)ethylamine (NEA), 1-hydroxybenzotriazole (HBT), $N, N^{\prime}$-dicyclohexylcarbodiimide (DCC) and $\alpha$-naphthaleneacetic acid (NAA) were obtained from Tokyo Kasei Kogyo (Tokyo, Japan). Other solvents and chemicals were of analytical or HPLC grade and used without further purification.

Synthesis of trans-OH-Taurine A solution of transOAc-taurine $(900 \mathrm{mg})$ in $\mathrm{MeOH}(20 \mathrm{ml})$ was added to a solution of $\mathrm{MeONa}(591 \mathrm{mg})$ in $\mathrm{MeOH}(30 \mathrm{ml})$ at room temperature with stirring, and the mixture was heated at $40^{\circ} \mathrm{C}$ for $1.5 \mathrm{~h}$. The mixture was evaporated in vacuo, the residue was dissolved in a solution of conc. $\mathrm{HCl}(2.5 \mathrm{ml})$ in THF $(80 \mathrm{ml})$ and the solution was concentrated in vacuo. The residue was purified by silica gel column chromatography $(\mathrm{MeOH})$ to give trans-OH-taurine $(350 \mathrm{mg}, 43.2 \%)$ as white powder. ${ }^{1} \mathrm{H}-\mathrm{NMR} \delta\left(500 \mathrm{MHz}, \mathrm{CD}_{3} \mathrm{OD}\right): 0.86$ $(2 \mathrm{H}, \mathrm{m}), 1.05(2 \mathrm{H}, \mathrm{m}), 1.26(4 \mathrm{H}, \mathrm{m}), 1.42(1 \mathrm{H}, \mathrm{m}), 1.44$ $(3 \mathrm{H}, \mathrm{d}, J=7.3 \mathrm{~Hz}), 1.56(4 \mathrm{H}, \mathrm{m}), 1.71(2 \mathrm{H}, \mathrm{m}), 1.95(2 \mathrm{H}$, m), $2.21(1 \mathrm{H}, \mathrm{dd}, J=13.4,9.8 \mathrm{~Hz}), 2.97(2 \mathrm{H}, \mathrm{t}, J=6.7 \mathrm{~Hz})$, $3.19(2 \mathrm{H}, \mathrm{m}), 3.53(1 \mathrm{H}, \mathrm{m}), 3.66(2 \mathrm{H}, \mathrm{m}), 7.11(2 \mathrm{H}, \mathrm{d}$, $J=8.2 \mathrm{~Hz}), 7.22(2 \mathrm{H}, \mathrm{d}, J=8.2 \mathrm{~Hz})$. FAB-MS (negative ion): $m / z 368\left([\mathrm{M}-\mathrm{H}]^{-}\right)$.

Animals and Dosing Male beagle dogs $(10.5-12.5 \mathrm{~kg})$ 
were used after fasting for one night prior to administration. CS-670 and its enantiomers were dissolved in saline $(1 \mathrm{mg} / \mathrm{ml})$ and orally administered at doses of $2 \mathrm{mg} / \mathrm{kg}$ (CS-670) or $1 \mathrm{mg} / \mathrm{kg}$ (enantiomers) by a cannula tube. The tube was then washed with $20 \mathrm{ml}$ of distilled water. The animals were kept in a metabolic cage and urine samples were collected over $24 \mathrm{~h}$. The urine was stored at $-20^{\circ} \mathrm{C}$ until measurement.

Isolation of the Metabolite ${ }^{14} \mathrm{C}$-Labelled CS-670, which was diluted 50 -fold with unlabelled CS-670, was administered at a dose of $2 \mathrm{mg} / \mathrm{kg}$ in order to isolate the urinary metabolite, and the urine collected over $24 \mathrm{~h}$ came to $240 \mathrm{ml}$. To the urine was added $25 \mathrm{ml}$ of $1 \mathrm{M}$ acetate buffer $(\mathrm{pH} 5.2)$ and $20 \mathrm{ml}$ of Glusulase, and this was incubated for $24 \mathrm{~h}$ at $37^{\circ} \mathrm{C}$. The solution was adjusted to pH 3 with $4 \mathrm{~N} \mathrm{HCl}$, loaded onto an Amberlite XAD-2 column (bed volume 1.5l) and then washed with 31 of distilled water and eluted with 0.81 of methanol. The extracts were evaporated to dryness and the residue was reconstituted with $20 \mathrm{ml}$ of $10 \%$ methanol $/ 10 \mathrm{~mm}$ phosphate buffer ( $\mathrm{pH}$ 7.0) solution. The solution was loaded onto a Sephadex LH-20 column $(20 \times 500 \mathrm{~mm})$ and then eluted with $300 \mathrm{ml}$ of distilled water-methanol ( 0 to $100 \%$ ) using a linear gradient mode, in which each $8 \mathrm{ml}$ of eluate was fractionated until fr. 40 . The radioactive fractions (fr. 21 to 31) were mixed, and the methanol in the solution was evaporated and then lyophilized. The residue was dissolved in a small amount of $50 \%$ methanol and developed with the mixed solvents of $n$-butanol-acetic acid-water( $4: 1: 1)$ after spotting on a TLC plate (Kieselgel $60 \mathrm{~F}_{254}$, thickness $0.25 \mathrm{~mm}$, Merck). After contact with an imaging plate for $30 \mathrm{~min}$, TLC autoradiograms were made by BAS-1000 (Fuji Film Company). The radioactive fraction $(R f 0.5)$ was scraped, then extracted with methanol and evaporated. The residue was reconstituted with $0.5 \mathrm{ml}$ of methanol and further purified by HPLC [column, $\mu$ Bondapack $\mathrm{C} 18$ (Waters, $300 \times 20 \mathrm{~mm}$ i.d.); mobile phase, $0.1 \%$ trifluoroacetic acid (TFA)-methanol (50:50); flow rate, $1 \mathrm{ml} / \mathrm{min}$; detection, $\mathrm{UV}$ at $220 \mathrm{~nm}$. The fraction containing the metabolite was collected and concentrated in vacuo to yield the metabolite $(3.7 \mathrm{mg})$ as an amorphous powder.

Quantitative Determination of trans-OH-Taurine To $1 \mathrm{ml}$ of the collected urine was added $50 \mu \mathrm{l}$ of NAA $(100 \mu \mathrm{g} / \mathrm{ml})$ as an internal standard, and the sample was loaded onto a Bond Elut C18 (bed volume $3 \mathrm{ml}$, Analytichem International). It was then washed twice with $5 \mathrm{ml}$ of $0.1 \mathrm{M}$ acetate buffer $(\mathrm{pH} 2.5)$ and $5 \mathrm{ml}$ of distilled water, and then eluted with $2 \mathrm{ml}$ of methanol. The extracts were evaporated to dryness in vacuo. The residue was reconstituted with $0.2 \mathrm{ml}$ of $50 \%$ methanol and $20 \mu \mathrm{l}$ aliquots were injected onto HPLC. The HPLC conditions were as follows: column, YMC Pack ODS-A312 $(150 \times 6 \mathrm{~mm}$ i.d., YMC Company, Japan); mobile phase, $0.1 \%$ TFA-methanol $(50: 50)$; flow rate, $1 \mathrm{ml} / \mathrm{min}$; detection, UV at $220 \mathrm{~nm}$. trans-OH-Taurine was added to dog urine at concentrations of 10,50 and $100 \mu \mathrm{g} / \mathrm{ml}$. The urine samples were extracted and analyzed as mentioned above. The recoveries of trans-OH-taurine from urine were more than $93 \%$.

Enantiomeric Ratios of the 2-Arylpropionic Acid Side
Chain To $1.5 \mathrm{ml}$ of urine was added $150 \mu \mathrm{l}$ of both $1 \mathrm{M}$ acetate buffer (pH 5.2) and Glusulase $(0.15 \mathrm{ml})$, which was then incubated for $16 \mathrm{~h}$ at $37^{\circ} \mathrm{C}$. The solution was centrifuged after the addition of $6 \mathrm{ml}$ of methanol. The supernatant was concentrated and spotted on a TLC plate as mentioned above (Kieselgel $\mathrm{F}_{254}$, thickness $0.25 \mathrm{~mm}$ ). After being developed with the mixed solvents of $n$-butanol-acetic acid-water $(4: 1: 1)$, the taurine conjugate fraction was scraped and extracted with $5 \mathrm{ml}$ of methanol. After evaporation of the solvent, the residue was dissolved in $2 \mathrm{ml}$ of $6 \mathrm{~N} \mathrm{HCl}$ and refluxed for $2 \mathrm{~h}$. Then the solution was extracted with $2 \mathrm{ml}$ of toluene, and the extracts were evaporated to dryness in vacuo. Control experiments using authentic trans-OH-taurine showed that the acid hydrolysis was quantitatively carried out under the conditions used. The hydrolyzed product was further purified by HPLC [column; ERC-ODS-1282, $(250 \times 6 \mathrm{~mm}$, ERC, Inc., Japan), mobile phase; $\mathrm{CH}_{3} \mathrm{CN}-0.05 \mathrm{M} \mathrm{H}_{3} \mathrm{PO}_{4}$ (46:54), flow rate; $1 \mathrm{ml} / \mathrm{min}$, detection; UV at $220 \mathrm{~nm}$ ]. The peak corresponding to the metabolite was collected and concentrated. Then, after the addition of $2 \mathrm{ml}$ of $0.2 \mathrm{~N} \mathrm{HCl}$ and $2 \mathrm{ml}$ of ethyl acetate, the mixture was shaken with a Vortex mixer and the organic phase was evaporated to dryness in vacuo. Amide derivatization of the hydrolyzed product was performed according to the method reported by Takasaki et al. ${ }^{3)}$ Namely, the residue was mixed with $40 \mu \mathrm{g}$ of NEA, $80 \mu \mathrm{g}$ of HBT and $80 \mu \mathrm{g}$ of DCC in $220 \mu \mathrm{l}$ of dichloromethane-pyridine $(98: 2)$ and left to stand at room temperature for $1 \mathrm{~h}$. The reaction mixture was evaporated with a nitrogen stream and extracted with $0.5 \mathrm{ml}$ of ethyl acetate after the addition of $0.5 \mathrm{ml}$ of $0.1 \mathrm{~N} \mathrm{HCl}$. The organic layer was dried over anhydrous sodium sulfate, then $50 \mu \mathrm{l}$ aliqouts were injected onto HPLC. Analytical conditions were maintained as follows. The column used was ERC-Silica-1282 $(250 \times$ $6 \mathrm{~mm}$ i.d. ERC Inc., Japan), $n$-hexane-ethanol-1,2dichloroethane $(95: 5: 10)$ was used as a mobile phase, and the flow rate was maintained at $2 \mathrm{ml} / \mathrm{min}$. Detection was carried out by fluorescence at $\lambda_{\mathrm{Ex}} 283 \mathrm{~nm}$ and $\lambda_{\mathrm{Em}}$ $330 \mathrm{~nm}$.

Structure Analysis by MS and ${ }^{1} \mathrm{H}-\mathrm{NMR}$ MS: A JEOL SX-102qQ hybrid mass spectrometer was used for structural analysis of the metabolite. FAB-MS and FAB-MS/MS by the negative mode were carried out as follows. FAB-MS: primary ion, Xe; matrix, glycerol; acceleration voltage, $10 \mathrm{kV}$; and FAB-MS/MS: collisional activation gas (CAD), Xe; CAD pressure, $5 \times 10^{-5}$ Torr; collision energy, $50 \mathrm{eV}$.

NMR: A JEOL GX-500FT-NMR spectrometer (500 $\mathrm{MHz}$ ) was used. Samples were dissolved in deuterated methanol, and tetramethylsilane was used as an internal standard.

\section{RESULTS}

Structure Determination of trans-OH-Taurine Urine samples were collected from the dogs up to $24 \mathrm{~h}$ after oral administration of CS-670 at a dose of $2 \mathrm{mg} / \mathrm{kg}$. The samples were treated with Glusulase, and the polar metabolite was isolated by preparative TLC and HPLC methods. The isolated metabolite was subjected to 
FAB-MS analysis by the negative mode. A deprotonated molecular ion $[\mathrm{M}-\mathrm{H}]^{-}$was observed at $\mathrm{m} / \mathrm{z} 368$ in the spectrum shown in Fig. 1, suggesting the molecular weight of the metabolite to be 369 . Furthermore, as shown in Fig. 2, collisional activation of the $[\mathrm{M}-\mathrm{H}]^{-}$ion $(\mathrm{m} / \mathrm{z}$ 368) on MS/MS analysis produced characteristic fragment ions at $m / z 151\left(\cdot \mathrm{CONHCH}_{2} \mathrm{CH}_{2} \mathrm{SO}_{3}^{-}\right), \mathrm{m} / z 124$ $\left(\mathrm{H}_{2} \mathrm{NCH}_{2} \mathrm{CH}_{2} \mathrm{SO}_{3}^{-}\right), m / z 107\left(\mathrm{CH}_{2}=\mathrm{CHSO}_{3}^{-}\right), m / z 94$ $\left(\cdot \mathrm{CH}_{2} \mathrm{SO}_{3}^{-}\right)$and $m / z 80\left(\mathrm{SO}_{3}^{-}\right)$which correspond to the taurine moiety of the metabolite. The FAB-MS/MS spectrum was consistent with that of the authentic standard sample of trans-OH-taurine. Therefore, the isolated metabolite was presumed to be trans-OH-taurine; however, cis-OH, the stereoisomer of trans-OH, could not be negated as an aglycon from this result. Accordingly, the metabolite was examined by ${ }^{1} \mathrm{H}-\mathrm{NMR}$ (Fig. 3). Both

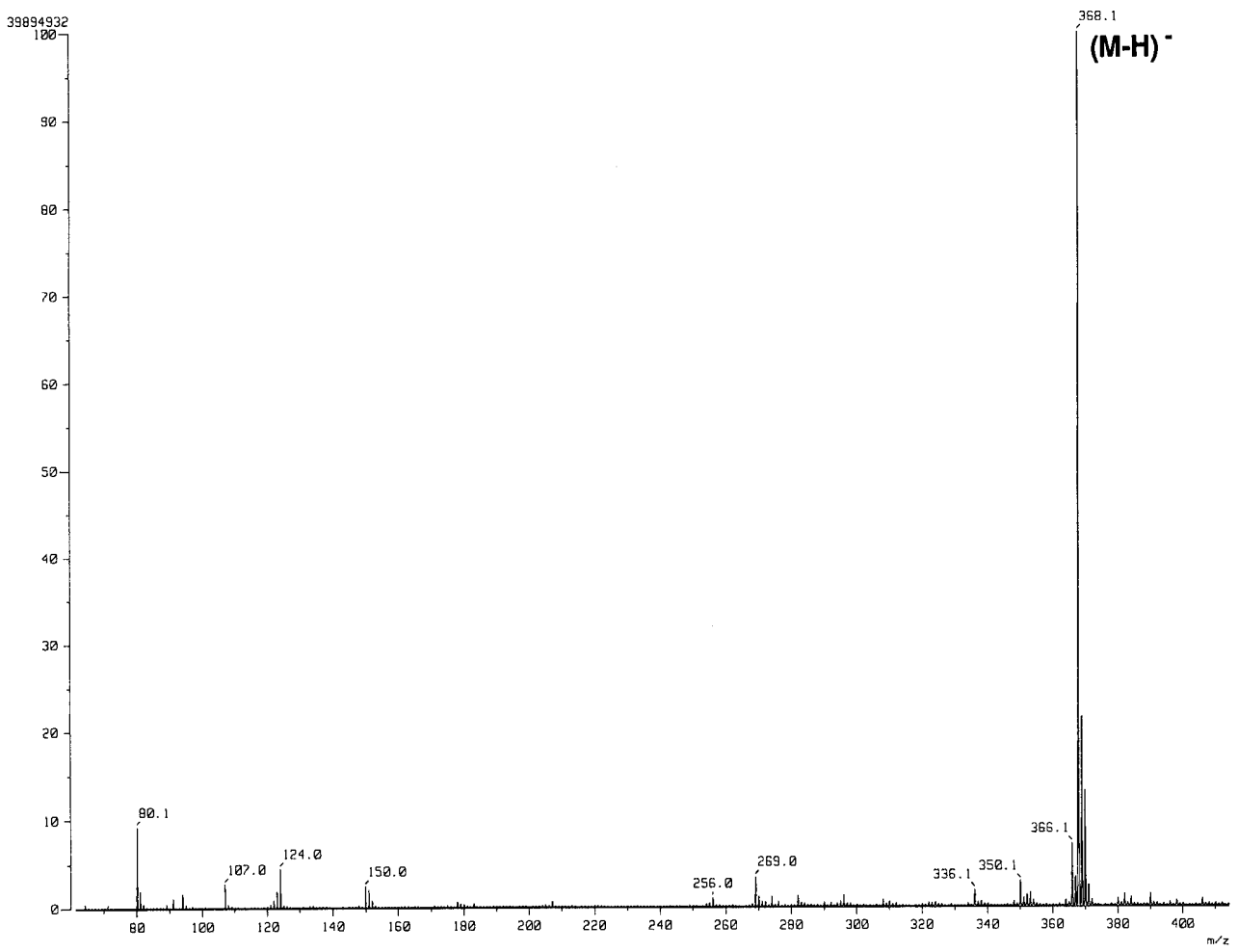

Fig. 1. FAB-MS Spectrum of trans-OH-Taurine Isolated from Dog Urine after CS-670 Dosing

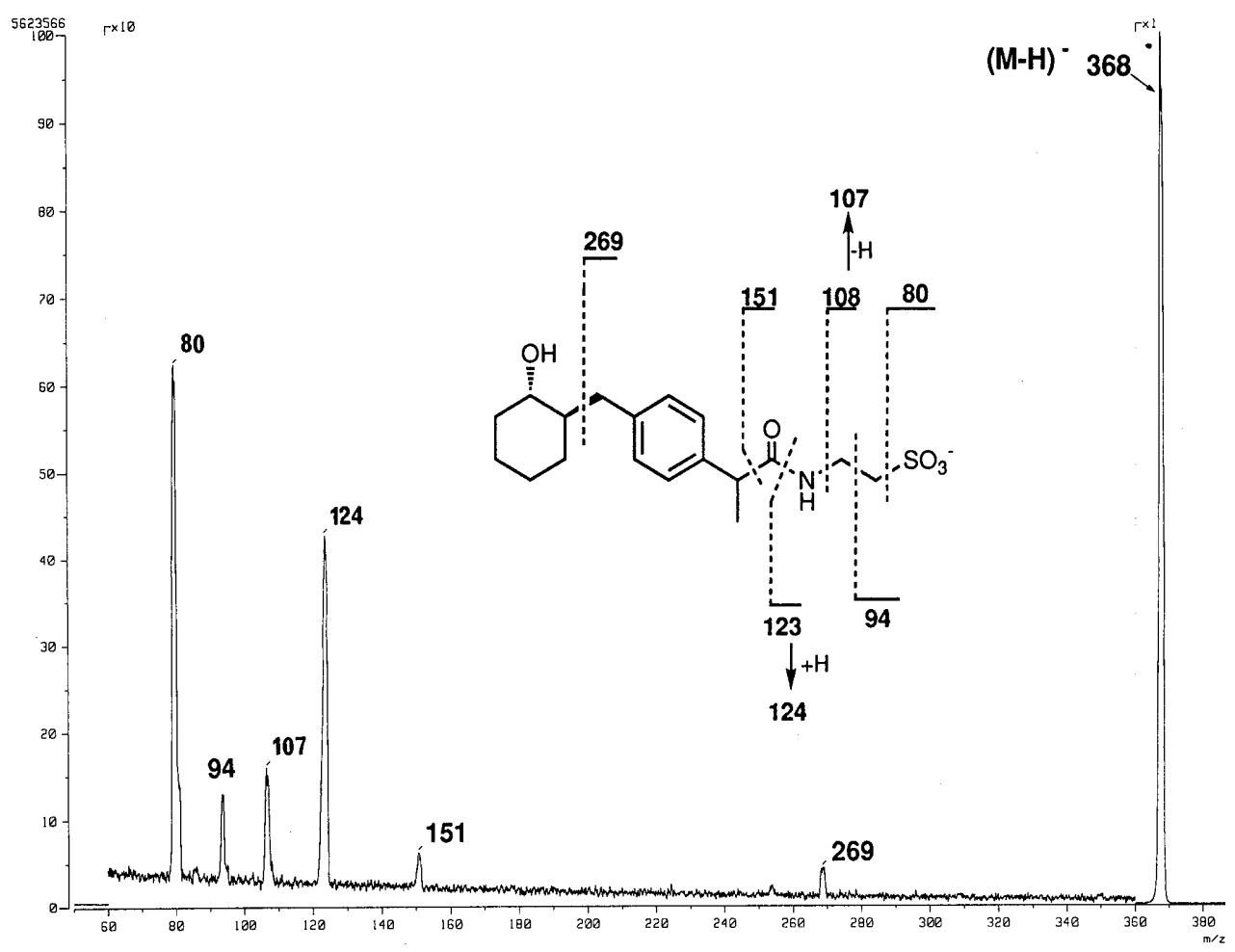

Fig. 2. FAB-MS/MS Spectrum of the $(\mathrm{M}-\mathrm{H})^{-}$Ion of trans-OH-Taurine Isolated from Dog Urine after CS-670 Dosing 


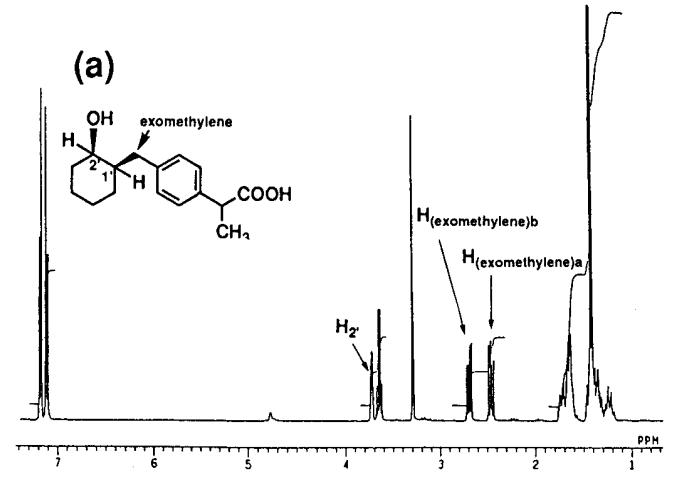

(b)
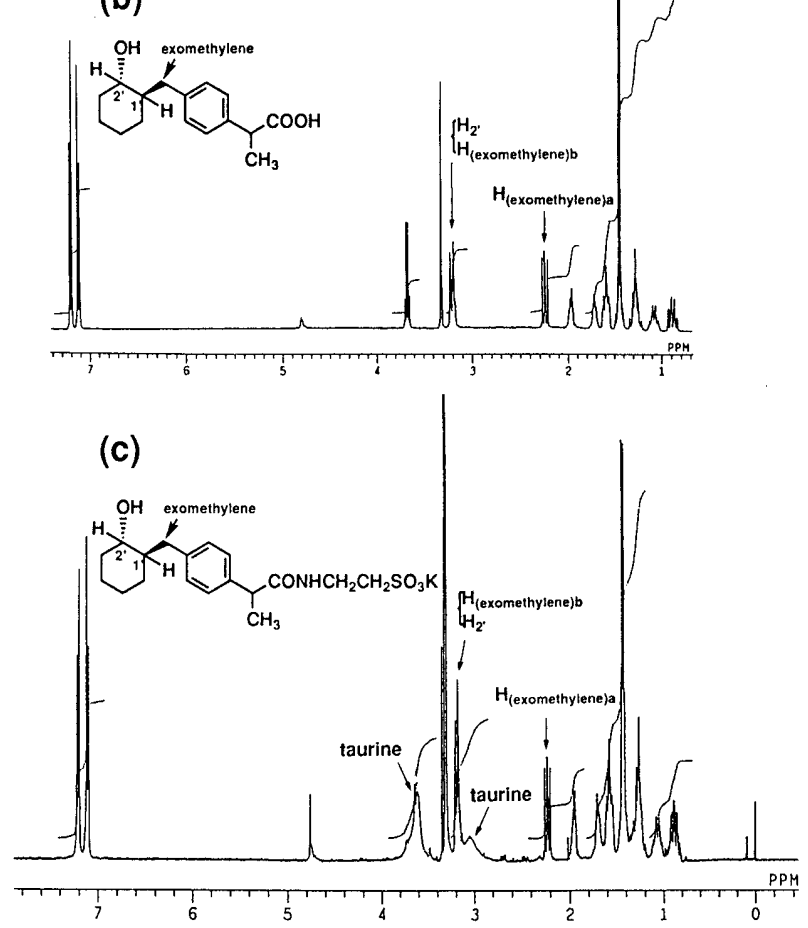

Fig. 3. NMR Spectra of cis-OH (a), trans-OH (b) and trans-OHTaurine (c) Isolated from Dog Urine after CS-670 Dosing

the mono-ols were clearly discriminated by assignment of the three characteristic protons of cis- $\mathrm{OH}$ and trans- $\mathrm{OH}$, the $1^{\prime}-\mathrm{H}, 2^{\prime}-\mathrm{H}$ protons of the cyclohexanol moiety and the exomethylene protons $\left(\mathrm{H}_{\mathrm{a}}\right.$ and $\left.\mathrm{H}_{\mathrm{b}}\right)$. The chemical shifts were assigned as follows: For trans- $-\mathrm{OH}, 1^{\prime}-\mathrm{H}, 2^{\prime}-\mathrm{H}, \mathrm{H}_{\mathrm{a}}$ and $\mathrm{H}_{b}$ appeared at $1.43,3.20,2.23$ and $3.20 \mathrm{ppm}$, respectively. For $c i s-\mathrm{OH}$, the corresponding chemical shifts were detected at $1.65,3.75,2.47$ and $2.70 \mathrm{ppm}$. The chemical shifts of the three protons of the isolated metabolite were observed at $1.44\left(1^{\prime}-\mathrm{H}\right), 3.20\left(2^{\prime}-\mathrm{H}\right), 2.23$ $\left(\mathrm{H}_{\mathrm{a}}\right)$ and $3.20 \mathrm{ppm}\left(\mathrm{H}_{\mathrm{b}}\right)$, which agreed with those of the authentic trans-OH. From these results, the metabolite isolated from dog urine was identified as trans-OH-taurine.

Quantitative Determination of trans-OH-Taurine Urinary trans-OH-taurine was well separated by HPLC without interference peaks from urine, as shown in Fig. 4 . The amount and enantiomeric ratios of the trans-OHtaurine excreted in the urine from 0 to $24 \mathrm{~h}$ after the administration of CS-670 (racemate) and its enantiomers were determined (Table 1). The extent of trans-OH-taurine excreted after administration of CS-670 was $59.7 \%$ of the dose in urine. This value almost agreed with the result (a)

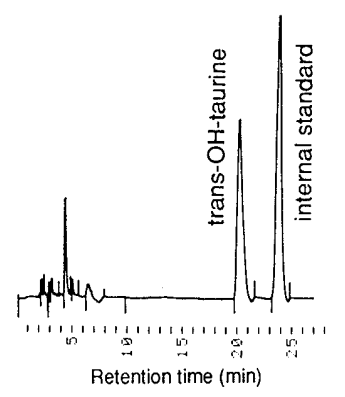

(c)

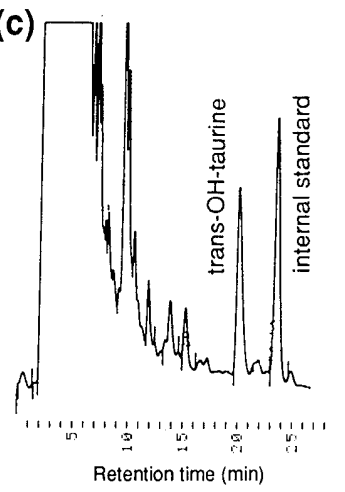

(b)

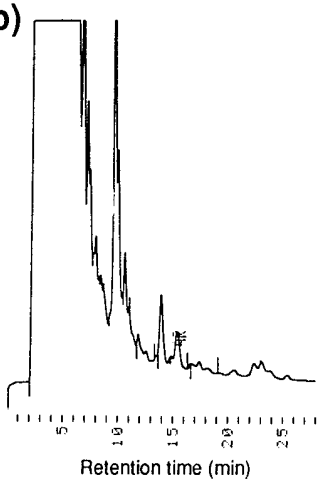

(d)

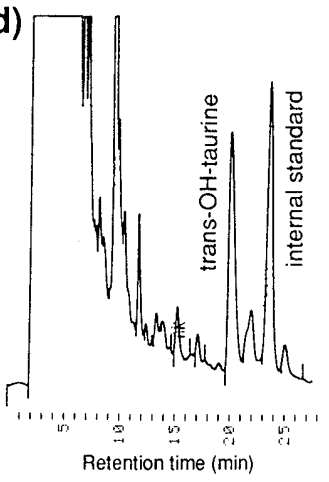

Fig. 4. HPLC Chromatograms of Authentic trans-OH-Taurine (a), Control Urine (b) and Urine after Administration of (2R)-CS-670 (c) and $(2 S)$-CS-670 (d) to Dogs

Table 1. Urinary Excretion and Enantiomeric Ratios at C-2 of trans$\mathrm{OH}-$ Taurine in Dogs after Oral Administration of CS-670 $(2 \mathrm{mg} / \mathrm{kg})$

\begin{tabular}{lcc}
\hline $\begin{array}{c}\text { Administered } \\
\text { CS-670 }\end{array}$ & \% of dose & $S / R$ ratio \\
\hline Racemate & $59.7 \pm 12.4$ & - \\
(2R)-Enantiomer & $47.2 \pm 3.7$ & $98.7 \pm 0.4 / 1.3 \pm 0.4$ \\
(2S)-Enantiomer & $70.9 \pm 3.2$. & $99.5 \pm 0.1 / 0.5 \pm 0.1$ \\
\hline
\end{tabular}

Mean \pm S.E. of three dogs. --: not tested.

using ${ }^{14} \mathrm{C}$-labelled CS-670. ${ }^{1)}$ On the other hand, trans-OH-taurine was also excreted in the urine after the administration of both CS-670 enantiomers as follows: $47.2 \%$ and $70.9 \%$ of the dose for the $(2 R)$ - and $(2 S)$-enantiomers, respectively.

Enantiomeric Ratios of the 2-Arylpropionic Acid Side Chain The trans-OH-taurine was hydrolyzed with $6 \mathrm{~N} \mathrm{HCl}$, the free carboxylic acid produced was derivatized to the amide diastereomer by reaction with a chiral amine reagent, NEA, and the derivatives were then determined by HPLC. The HPLC chromatograms and the $S / R$ ratios of the 2-asymmetric carbon are shown in Fig. 5 and Table 1. On hydrolysis with a strong acid, it was confirmed that racemization did not occur using the authentic taurine conjugate of (2S)-trans-OH. The $S / R$ ratio of the 2-asymmetric carbon on the trans-OH-taurine excreted in urine after the administration of ( $2 R$-CS-670 was 98.7/1.3. Similarly, the $S / R$ ratio at the 2-position on the trans-OH-taurine after a dosing of (2S)-CS-670 was $99.6 / 0.4$. Thus, it was found that the configuration of the 2 -asymmetric center was almost entirely $(S)$, regardless of 

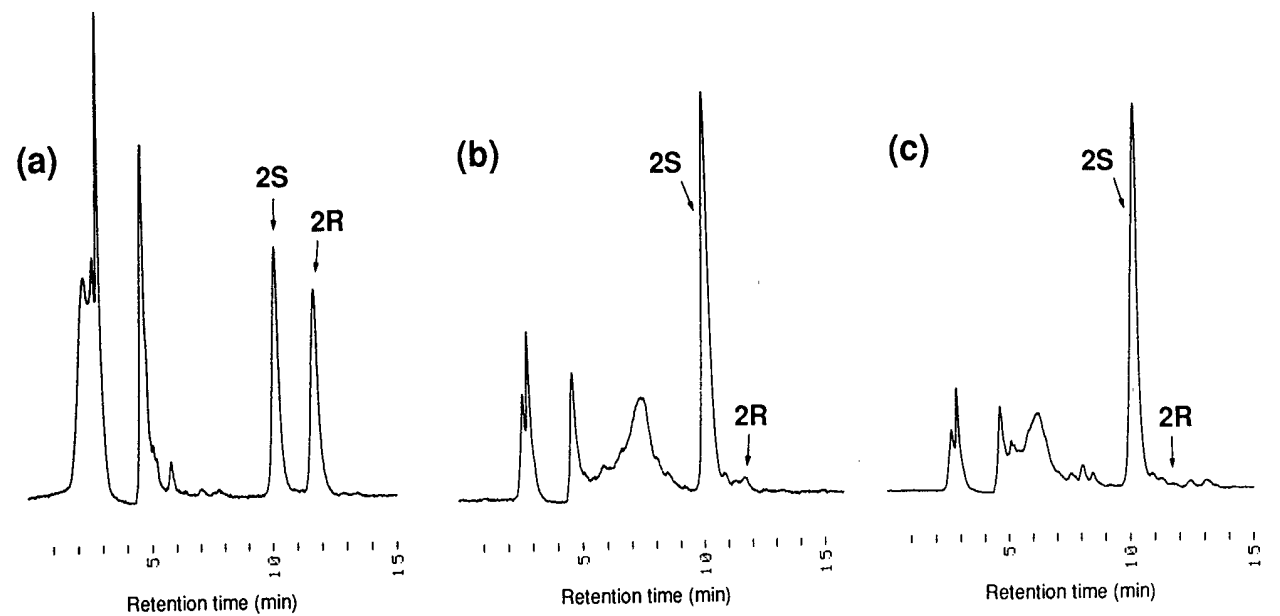

Fig. 5. Typical HPLC Chromatograms of (+)-(R)-1-(1-Naphthyl)ethyl Amides of Authentic trans-OH (a) and Acid-Hydrolyzed Products of trans-OH-Taurine Isolated from Dog Urine after $(2 R)$-CS-670 (b) and (2S)-CS-670 (c) Dosing

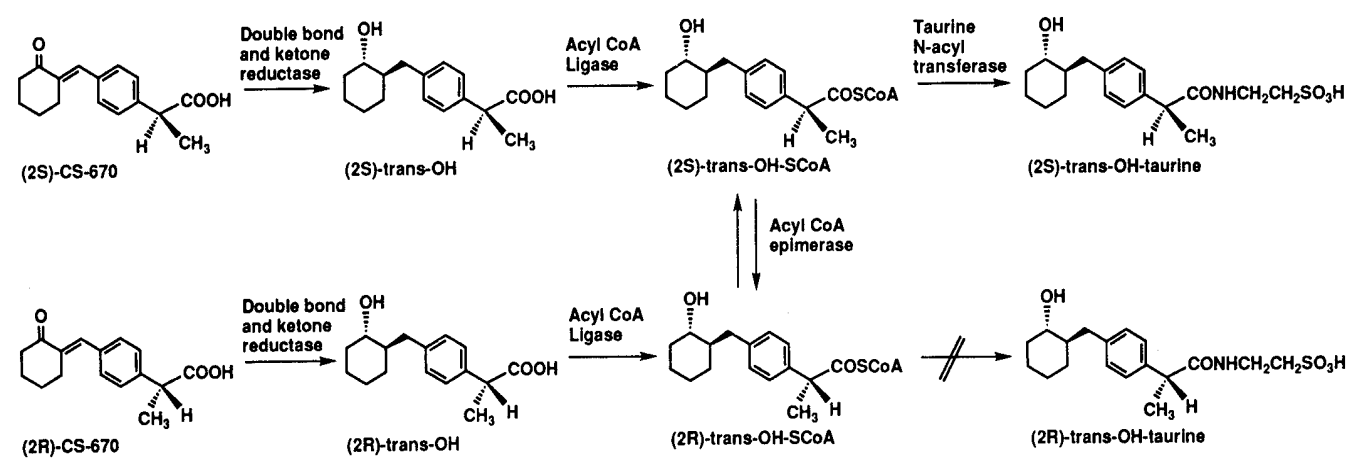

Fig. 6. Possible Mechanisms of Stereospecific Formation of (2S)-trans-OH-Taurine from (2S)- and (2R)-CS-670 in Dogs

the optical configuration of the CS-670 enantiomer administered.

\section{DISCUSSION}

From disposition studies on CS-670 in dogs using a ${ }^{14} \mathrm{C}$-labelled compound, a polar metabolite which is not hydrolyzed with Glusulase and mild alkaline treatment has been suggested to exist in urine. ${ }^{1)}$ The metabolite possessed $80 \%$ of the radioactivity in urine collected over $12 \mathrm{~h}$. Structural analysis by FAB-MS and ${ }^{1} \mathrm{H}-\mathrm{NMR}$ after isolation from dog urine revealed the metabolite to be the conjugated metabolite with taurine and trans- $\mathrm{OH}$ which was first produced by a reduction of the double bond and ketone group of CS-670. trans-OH-Taurine was detected as the main metabolite in all urine collected after the administration of CS-670 and its enantiomers.

The carboxyl group must be activated to the CoA thioester by acyl CoA ligase when compounds containing a carboxyl group are metabolized to the amino acid conjugate. ${ }^{4)}$ It has been reported that the $(2 R)$ configuration of many 2-arylpropionic acid anti-inflammatory drugs, such as ibuprofen, is unidirectionally inverted to the $(2 S)$-configuration. ${ }^{5-8}$ From investigations into the mechanism for this, the initial step of the chiral inversion was found to be stereospecific CoA thioesterification of the $(2 R)$-enantiomer by acyl CoA ligase. ${ }^{9)}$ That is, the $(2 S)$-enantiomer is not converted to the CoA thioester, therefore such chiral inversion does not occur. According to this mechanism, only the $(2 R)$ enantiomer should be transformed to the amino acid conjugates. However, the results of this study showed that the taurine conjugate was excreted as a main metabolite when the $(2 S)$-enantiomer was administered to dogs in addition to the $(2 R)$-enantiomer. Accordingly, it was suggested that both the $(2 R)$ - and $(2 S)$-enantiomers of trans-OH become substrates for acyl CoA ligase in dogs (Fig. 6). After the taurine conjugate was hydrolyzed under nonracemizing conditions, the free carboxylic acid produced was derivatized to the amide diastereomer, and the absolute configuration of the 2-propionic acid moiety was determined by HPLC. The 2-position was found to consist of almost all of the $(S)$-configuration when either of the enantiomers was administered. From this, the taurine $N$-acyl transferase responsible for taurine conjugation was suggested to be stereospecific for the $(2 S)$-CoA thioester. The trans-OH-taurine after administration of $(2 R)$-CS-670 could be produced through $(2 S)$-trans-OHSCoA which is formed from (2R)-trans-OH-SCoA by catalysis of acyl CoA epimerase.

We have studied the metabolism of 2-phenylpropionic acid (2-PPA) in dogs, it being selected as a model compound for profen NSAIDs, and reported that $(S)$ 2-PPA produced almost the same extent of glycine conjugate as $(R)-2-\mathrm{PPA}^{10}{ }^{10}$ Recently, the taurine conjugate of ibuprofen (IBP-Tau) was identified as a minor 
urinary metabolite $(1.52 \%$ of dose $)$ in humans by Shirley et al. ${ }^{1{ }^{1)}}$ It was demonstrated that IBP-Tau consists mainly $(c a .87 \%)$ in the $(S)$-configuration after oral dosing of the racemate, and further that the majority of the $(S)$-IBP-Tau was derived from $(S)$-IBP using a pseudoracemic mixture of the drug $\left[(R)-\mathrm{IBP} /(S)-\left[{ }^{2} \mathrm{H}_{3}\right]-\mathrm{IBP}\right]$. These results suggest that $(2 S)$-ibuprofen is converted to the acyl CoA intermediate in humans. Thus, it was demonstrated that not only 2-PPA, which has a simple structure, but also the $(2 S)$-enantiomers of real pharmaceuticals having rather complex structures, become the substrate for acyl CoA ligase. These results clearly indicate that the stereospecificity of acyl $\mathrm{CoA}$ ligase for the $(2 R)$ enantiomers is not necessarily true, depending on the chemical structures and animal species employed, and this may be due to multiforms of acyl CoA ligase. In dogs, 2-PPA was conjugated with glycine, whereas the trans-OH metabolite was conjugated with taurine. Thus, it was found that the species of amino acids used for amino acid conjugation of xenobiotics differed depending on the chemical structure, which may again suggest the existence of isoenzymes for the amino acid $\mathrm{N}$-acyl transferase.

Acknowledgements We wish to thank Dr. Yukinori Kawahara, the director of our laboratories, for his kind encouragement.

\section{REFERENCES}

1) Asami M., Nakajima E., Hayashi R., Takasaki W., Tanaka Y., Otsuki S., Takaichi M., Mitsui T., Hasegawa T., Yokoshima T., Xenobio. Metabol. Dispos., 10, 637-650 (1995).

2) Asami M., Yamamura M., Takasaki W., Tanaka Y., J. Chromatogr. Biomed. Appl., 665, 107-116 (1995).

3) Takasaki W., Asami M., Muramatsu S., Hayashi R., Tanaka Y., Kawabata K., Hoshiyama K., J. Chromatogr. Biomed. Appl., 613, 67-77 (1993).

4) Caldwell J., "Conjugation Reactions in Drug Biotransformation," ed. by Atio A., Amsterdam, Elsevier/North Holland, 1978, pp. $111-120$.

5) Nagashima H., Tanaka Y., Watanabe H., Hayashi R. Kawada K., Chem. Pharm. Bull., 32, 251-257 (1984).

6) Hutt A. J., Caldwell J., J. Pharm. Pharmacol., 35, 693-704 (1983).

7) Hutt A. J., Caldwell J., Clin. Pharmacokinet., 9, 371-373 (1984).

8) Caldwell J., Hutt A. J., Fournel-Gileux S. F., Biochem. Pharmacol., 37, 105-114 (1988).

9) Nakamura Y., Yamaguchi T., Takahashi S., Hashimoto S., Iwatani K., Nakagawa Y., J. Pharmacobio-Dyn., 4, S-1 (1981).

10) Tanaka Y., Shimomura Y., Hirota T., Nozaki A., Ebata M. Takasaki W., Shigehara E., Hayashi R., Caldwell J., Chirality, 4, 342-348 (1992).

11) Shirley M. A., Guan X., Kaiser D. G., Halstead G. W., Baillie T. A., J. Pharmacol. Exp. Ther., 269, 1166-1175 (1994). 